\title{
Make Public Spaces Great Again Using Social Innovation Reflections from the Context of Downtown San Diego as a Cultural District
}

\author{
Israa H. Mahmoud $^{(\bowtie)}$ (D) and Carmelina Bevilacqua (D) \\ Mediterranea University of Reggio Calabria, 89100 Reggio Calabria, Italy \\ israa.hanafi@unirc.it
}

\begin{abstract}
This paper investigates the role of public spaces in spurring innovation and promoting entrepreneurial activities in Downtown San Diego urban context as a distinguished "cultural district". The idea that in creative cities, flourishing human capital, when coupled with incremental quality of life, could be the driving vehicle to social innovation and economic prosperity. On that public spaces are a cross cutting phenomenon in a lifetime cycle, through which their success could be evaluated contextually based on their formation and implementation policies, and how they work-out to be social innovation catalysts. Hence, this paper studies contextually the Downtown San Diego Partnership (DSDP) and their role to activate and regenerate different public spaces in downtown area to foster economic development. Two successful exemplar cases are studied; to better understand the dynamics by which the cultural programming in urban parks through events occurrence in Downtown as vibrant cultural hub; as well as the focus on a co-working and incubator space as a successful case to explain the human capital attraction to the Downtown area. The conclusions draw on an evaluation matrix of analysis that investigates the Catchment area/Sphere of influence falling in San Diego Downtown area, and helps to reach the envisioned opportunities and the policy measures applied to foster social innovation in those public spaces, and evaluate the success or failure of the Downtown San Diego Partnership to boost the innovation ecosystem.
\end{abstract}

Keywords: Public spaces $\cdot$ Social innovation ecosystem $\cdot$ Co-working spaces

\section{Introduction}

While the role of public spaces in catalyzing entrepreneurial activities and spurring innovation is undebatable, the correlation between the social innovation and 'terri-torial milieu' remained under investigation for an academic decade [1]. However, the need for a place-based approach to better understand the spatial dimension in perceiving and accelerating the opportunity for social innovation Ecosystem remained significant. Yet, different key-factors interfere when it comes to social innovation and its' territorial milieu such as governance of public spaces, localization of innovation spaces, as well as the space territorial connectedness and network [2]. In that sense, this paper is structured as follows: the first part introduces the social innovation concept into the 
research of Public spaces and how the locational factors help build the cultural districts profile.

The second part focuses on the Spatial context of downtown San Diego and displays both cases of the urban park "Courtyard" and the Co-working space "Downtown Works". The third and last part discusses the findings and the conclusions based on criterion evaluation matrix and measurement tools.

\section{Public Spaces Role as Catalyst for Social Innovation}

A promotional approach in the field shows an interest in cultural hubs and Districts where public spaces formation act as a melting pot for creative industries clusters. The role that creative city spaces act behind scientific policy rationales, claims the share in the knowledge economy and the cultural ranking of a city [3]. Meanwhile, those cultural hubs develop themselves in a later phase - in basis of their context, quality of life, identity, uses and programming- to act as catalyst, physically and virtually, for inward investment, business location decisions [4] and most importantly for human capital attraction that shape the social innovation environment and ecosystem (see Fig. 1).
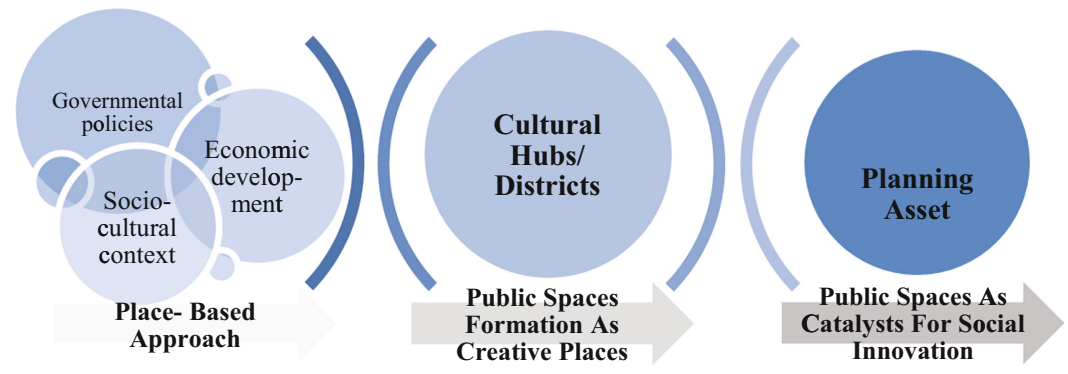

Fig. 1. Cultural hubs formation lifecycle dynamics (Source: the authors, May 2017)

Accordingly, with the role that public spaces should keep tenure of some combined factors of technological innovation, amenities, public services, and a certain level of social inclusion and lifestyle diversity. In a broader sense, those cultural hubs come to be seen as a strategic urban planning asset [5,6]. Afterwards, those assets distinguish certain public spaces from others based-on context formation policies, cultural programming, sphere of influence/catchment area and stakeholders. Contrariwise, it is undeniable the fact that while some Public spaces might be strategic planning assets, might as well play a role in increasing income inequalities, gentrification, and economic segregation $[7,8]$.

The Un-Habitat [9] amends the measurement of quality of public spaces by anchoring the urban policies, governmental synergies, and usage of public spaces as a catalyst for economically growing vibrant cities. Quality public spaces-including 
streets, urban parks, courtyards- are multi-functional joints for social interaction, economic exchange, and theatre for cultural diversity expression.

In that perception, on one hand the role of quality public spaces is pivotal in improving living conditions of urban populations. Locational factors attract knowledge, industry businesses, qualified and creative workforce, and tourism as highlighted in Leipzig Charter for Sustainable cities [10]. Therefore, the interaction between public spaces and planning policies when coupled with infrastructure must ultimately improve in order to create attractive, user-oriented public spaces and achieve a higher standard living environment.

Nonetheless, on the other hand the definition of Social innovation as an approach for individual and collective wellbeing can be elaborated into three interconnected features [11]: first, the satisfaction of human needs (both material and non- material); second, social relations between individuals and groups at different spatial scales; third, empowerment, with micro level initiatives bringing positive macro level change. Spatial scale, therefore, has a strong role in the emergence and effectiveness of socially innovative actions, especially in terms of the level of intervention [12, 13].

\section{A Spatial Focus on Downtown San Diego Urban Context}

The urban fabric of San Diego- either as a county or MSA-is very diverse and merely, touristically, vivacious in some areas. The contextual study showed the verification of two evaluation criteria: (1) increase in quality of life and (2) attraction of human capital that create the vibrancy that -consequently- attracts the professional pool of labor. Downtown San Diego offers a variety of cultural and social amenities that explains the reason why downtown is exponentially growing as a regional urban core [14].

The spatial focus in this paper goes to the Downtown area; geographically defined as the Downtown Community Planning Area (CPA), Zip Code 92101. Roughly an area of 1,450 acres and encompasses seven thriving neighborhoods, each with its own unique identity (see Fig. 2 - left). Statistically speaking, Downtown is home to 35,000 residents and a growing population of $97 \%$ since 2000 , notably a dominance of $51 \%$ for highly educated residents and 73\% high-earning professionals, [15]. A remarkable attribute to downtown San Diego area is the constant physical and economic development in progress, the city efforts to develop a walkable "live, work and play" urban core. Nonetheless, the area has a potential growth, the city government hired one of highly ranked architectural and urban design firm to overlook the redesigning of the downtown skyline from North to South [16].

In a matter of fact, Downtown San Diego has a $90 \%$ score in walkability; $78 \%$ of residents enjoy its central location [17, 18]. Proximity to different venues of arts and culture as well as other amenities in downtown area makes it attractive to entrepreneurs. The San Diegan Downtown vibrancy is unmistakable; that noted, leads to social innovation; the evidence-based is demonstrated through the two evaluation criteria: the increase in quality of life and the attraction to human capital, as described as "creative class" and Knowledge-based workers. 


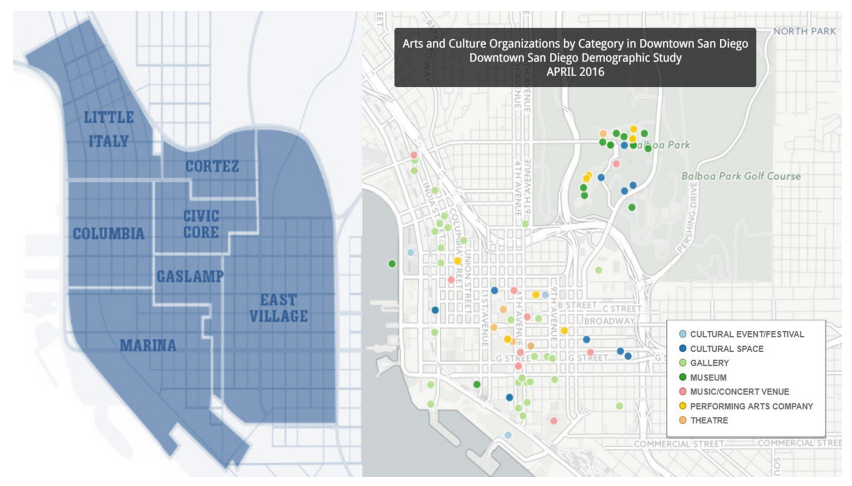

Fig. 2. Downtown San Diego seven neighborhoods (left) (Source: the authors, 2016) -Arts and cultural organizations Cluster in Downtown San Diego (Right). (Source: [19])

\subsection{Downtown San Diego Partnership Focus Area}

One of the most prominent cases of those cultural districts in the Downtown area, whereas the Downtown San Diego Partnership (DSDP)-a nonprofit organization-is spatially focused and operating. That adds up to the approach explained earlier of public spaces lifetime cycle where the place-based is transformed into implementation-based through privileged partnerships and associated stakeholders. The following part of this paper examines on the ground scale of the downtown area whereas the evaluation of key factors for the creation of the Cultural Hub/District is observed to verify the role that public spaces are playing in forming creative places that turn to be catalyst for social innovation in San Diego area.

In a study conducted by UC San Diego extension center for research on the regional economy in (2016) [14] about the San Diego Downtown prosperity, the area demonstrated a concentration of 92 arts and cultural destinations and organizations in the urban core. A diversity of venues types between 31 art galleries, 4 museums, 6 live performance theatres, 12 music venues and 10 performing arts groups, including a symphony, an opera, and a professional ballet company. The neighboring Balboa Park boasts upwards of 30 arts and cultural destinations within its boundaries as well (see Fig. 2- right).

While Downtown San Diego demonstrates itself as a cultural hub and performance arts hotspot, $79 \%$ of residents enjoyed being to a proximity to that ambient. These individuals attend activities such as musical entertainment (74\%), museums (74\%), movies (69\%), performance arts (67\%) and art galleries/events (61\%), [14].

The Phenomenon that is occurring in downtown San Diego being transformed in an arts and culture hotspot nowadays in not a laissez-faire. The American planning association (APA) coined the concept in 2015 by highlighting the facts that entre-preneurial activities seek out communities that inspire creativity and push boundaries. That, being correlated by business firms location with artists and cultural facilities together, has a resulting 'multiplier effect', driving further the innovation economy and economic vitality by measurable outcome [20]. In fact, the role that 
Downtown San Diego Partnership plays in forming and pushing the cultural scene vitality is un-deniable, relating between cultural-sector firms and creative professionals, along with improving and developing physical facilities deliberates a shared economic advantage to downtown area in that sense.

Urban Parks Model: The Quartyard Case Study. Another example for the spatial concentration of cultural events occurrence and venues clustering in Downtown area is observed in the "urban park" namely "Quartyard". A 25,000-square foot city owned lot at 1102 Market street, constructed in 2014 from repurposed shipping containers in East Village at downtown (see Fig. 3). The public space, with a 1000 persons' minimum capacity, is home to a coffee shop, restaurant, dog park, beer garden, music venue and a rotating assortment of food trucks. Basically, promoting themselves as a venue that brings people together, celebrates community, coffee, food, music, and cultivates the culture of unique social gatherings. Open 7 days a week, Quartyard plays host to numerous cultural events from farmers', pop-up markets to movie nights, film festivals and music outdoor concerts.
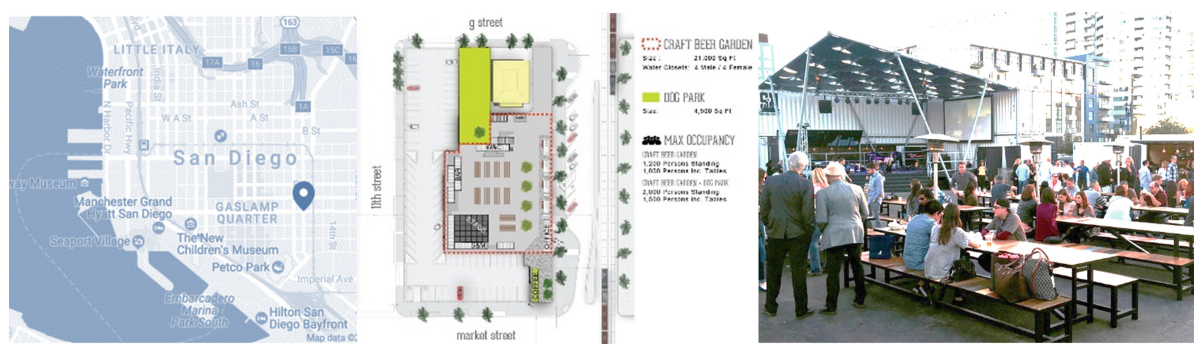

Fig. 3. Quartyard Urban Park location, site design and inside views during an event - from left to right. (Source: the authors, May 2017).

The interesting attribute in the Quartyard urban park example is its' formation as a "communal" public space. As reported by Lothspeich [21], three senior architectural students in 2013 concepted the idea of a "Movable Urban Park". The idea was simple, that is transform vacant city land into a thriving public space that could be assembled quickly, and torn down just as fast, using shipping containers as structural components instead of spending the time, money and effort required to develop an actual building. While missing on financial means, the trio raised funds on kickstarter (an online crowd sourcing platform), $\$ 60,000$ were campaigned online and in person to prove residents' interest in the project to the city, after gathering investors, partnering with contractors, and receiving legal approval from the city, the urban park was born to light and given the name of "Your City Block".

Co-Working Spaces Model: Downtown Works Case Study. Nonetheless, the same importance of cultural events occurrence is equally measured by successful co-working spaces spreading, the diffusion of these spaces in the San Diego downtown area nowadays is remarkable. One of the highly ranked amongst the entrepreneurial community is Downtown Works, physically located in 550 West B Street 4th Floor San 
Diego, CA 92101. The two floors, 5,000 square feet Co-Working space offers tailored services for entrepreneurs and companies located in the venue; plans vary based on startups size and budget. Monthly, daily, permanent, or virtual offices are amongst options; open-desks, exclusive desks, or private offices and meeting rooms as well (see Fig. 4). Members benefit from a variety of amenities, a pet friendly space, on site market and a 24/7-member access [22].
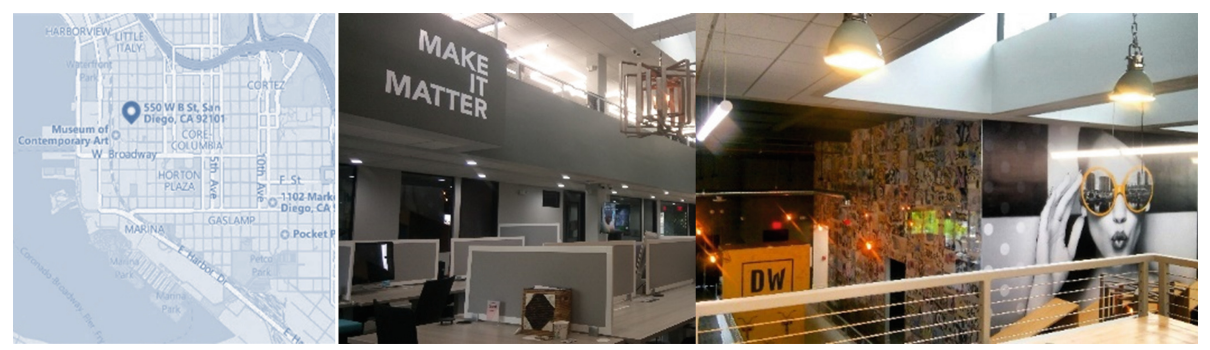

Fig. 4. Downtown works location and views from inside the co-working space - from left to right. (Source: the authors, 2017.)

Besides the physical amenities and the proximity to public transportation, and having the view of the San Diego port, Downtown Works [23] has an in-house accelerator program for startups. Weekly "lunch-n-learn" meetings with tech industry experts to promote the startups exposure to the business community, and to provide hands on experience with advisors and funding to startups.

In an Interview with one of the space founders "Wolf Bielas" conducted May 23 rd, 2017, he highlighted the importance of co-working spaces venues to the vibrancy of the entrepreneurial scene in San Diego Downtown that matches with "live, work, play" vision of the city and with entrepreneurs needs above all. Another crucial factor of co-working spaces in his opinion was the collaboration among co-working spaces venues rather than competition in the startups scene.

Within the same concerns of Bielas, he emphasized the fact that the cultural diversity and walkability atmosphere of Downtown San Diego is significantly high in comparison to other cities. Yet, the downtown San Diego area is relatively cheap in office rent prices for newly created startup and companies to get located:

"Nonetheless, there is an attraction of slowly growing investments in the area due to connection of software engineers to labor pool, even if the wage is 30\% less than San Francisco, for example, but the cost of living is $50 \%$ less than Bay area"

Interestingly, he stressed out the cross-border relationship connection with Tijuana and how this territorial proximity helps the software, hardware, and firmware talented labor pool in common to develop and prosper. Same notion happened around the dynamics of economic activities and local services clusters, (food, art, cultural venues, and shopping, etc.), which affected the local community gatherings scene. On the contrary, he highlighted the missing effect of an educational institution as an anchor in spreading the diffusion of startups, coupled with the missing fact of an anchor company 
headquarter that would attract other startups types to cluster and develop in downtown area.

Another stimulating fact in this interview was about the public policies and local governmental approach to facilitate the investment in Co-Working spaces and real estate development around Downtown area. Bielas referred to downtown area being exposed to a "perfect storm", whereas the mayor and the city strategic plans are very pro-development by supporting changing in some zoning regulations and giving permits facilitations to have new mixed-use buildings available for housing, small businesses, and a diversity of arts and cultural venues, together with a variety of retrofitting facilitations for existing buildings in the Downtown area.

In sum, the success of Downtown Works model gives an important retrospective about how the Public-Private interrelation is driving the innovation ecosystem of startups and entrepreneurs to flourish in Downtown area. Whiles the Private sector is a Pushing actor to the Public sector and how this controversial relationship has its' impact over the territorial milieu and social innovation ecosystem.

\section{Findings}

It is visible to eyesight the uniqueness art and cultural hub of Downtown San Diego; the social demographics data show a certain attraction to art hotspots where the urban vibrancy could be easily measured and perceived such as in urban parks models. While the evidences explain the human capital attraction phenomenon, the closest measurable and tangible criterion was the multiplier of startups in downtown area and how innovation ecosystem is pacing out in Downtown area.

The above-mentioned evaluation matrix (see Table 1), shows the measurement tools used in this research to identify the success or failure based on evaluation criteria that follows the conceptual model of cultural districts introduced earlier. Through the verification of implementation-based approach, the physical attributes in Downtown San Diego area showed a proximity to transportation, high walkability score, vicinity to different amenities; and that, fortifies the fact that a strong cultural District is flourishing, giving way to prosper economic development.

The hurdles to public spaces development are mostly financial; however, the city is tapping into local redevelopment funds, private donations, and economic recovery act to strengthen and transform the downtown area into a vibrant cultural hub [24]. Meanwhile, apart from the strengths in the territorial context, the wage multiplier effect for innovative jobs, lower rent prices and competitive advantages for startups are striking reasons, and for that, the downtown area has a wider sphere of influence/catchment area and is "baby-booming" in some specific innovation economy sectors such as software, tech and IT [25, 26]. Nonetheless, the rippling effects of the innovation scene is not limited to downtown area, the latest published Kauffman Index about metropolitan areas and city trends in startup activity unveiled a growing drift in San Diego metropolitan region. Among 39 innovative regions, San Diego ranked 4th based on rate of new entrepreneurs in market, opportunity share and startups density; thus looking willingly to join the parade of innovative cities [27]. 
Table 1. Evaluation analysis matrix for downtown San Diego case study (source: the authors)

\begin{tabular}{|c|c|c|c|}
\hline \multicolumn{4}{|c|}{ Downtown San Diego case study summary } \\
\hline Concept & Criteria of evaluation & Measurement tool & Assessment results \\
\hline $\begin{array}{l}\text { Place-based } \\
\text { approach }\end{array}$ & $\begin{array}{l}\text { - Socio-cultural context } \\
\text { - Governmental policies } \\
\text { - Economic development }\end{array}$ & $\begin{array}{l}\text { - Demographical } \\
\text { context } \\
\text { - Arts and cultural } \\
\text { hotspots } \\
\text { - Open spaces and Parks }\end{array}$ & $\begin{array}{l}\text { - Proximity to } \\
\text { transportation, } \\
\text { - High walkability } \\
\text { score, } \\
\text { - Vicinity to amenities }\end{array}$ \\
\hline $\begin{array}{l}\text { Cultural } \\
\text { hubs/districts }\end{array}$ & $\begin{array}{l}\text { - Quality of life increase } \\
\text { - Human capital } \\
\text { attraction }\end{array}$ & $\begin{array}{l}\text { - Vibrant spaces in area } \\
\text { - Startups located in } \\
\text { area }\end{array}$ & $\begin{array}{l}\text { - Effective planning } \\
\text { strategies and } \\
\text { facilities towards } \\
\text { mixed-use } \\
\text { developments }\end{array}$ \\
\hline $\begin{array}{l}\text { Implementation - } \\
\text { based approach }\end{array}$ & $\begin{array}{l}\text { - Cultural Programming } \\
\text { - Stakeholders } \\
\text { involvement } \\
\text { - Sphere of } \\
\text { influence/catchment } \\
\text { area }\end{array}$ & $\begin{array}{l}\text { - Cultural Events } \\
\text { occurrence } \\
\text { - The rippling effects of } \\
\text { innovation scene. }\end{array}$ & $\begin{array}{l}\text { - Diversity in } \\
\text { implementation } \\
\text { techniques } \\
\text { - Cross-border labor } \\
\text { relations, } \\
\text { - Missing Educational } \\
\text { Anchor institution }\end{array}$ \\
\hline
\end{tabular}

\section{Conclusion}

Fundamentally, Social innovation is deeply intertwined with privileged public services, public facilities, social inclusion, and lifestyle diversity where the public spaces are proved to be granular catalysts for sharing knowledge and building innovation [28]. While Cultural Hubs/districts are proven to be a driver for cultural-led urban policies [29], it is undeniable that the context diversification in Downtown San Diego area affect positively the two measurable criteria used to verify the implementation-based approach, that are: the increase of quality of life and Human Capital attraction. On one hand, Downtown San Diego Partnership plays a protagonist role as a public-private partnership in terms of public policies and community development through different engagement techniques to regenerate and activate different public spaces in connection with art and culture venues in downtown. On the other hand, the private sector is still pacing out the road while public bodies such as civic san Diego follow out the changes on the ground, yet the cultural vibrancy is undeniable.

Two notable outcomes from the interviews and the physical observation analysis show that: (1) downtown area lacks an anchor educational institution that drives a lot of economic activities within neighboring areas, (2) governmental facilitations to business development either in urban planning policies or land-use zoning regulations differ on basis of projects. Private businesses have easier trends to obtain permissions for mixed-use developments and retrofitting projects. (3) the Community plan as approached by public administration (e.g. CCDC) is merely tokenism with no ground.

In sum, Downtown san Diego area is a set stage to development of public spaces bringing to renaissance a vibrant urban core; constraints are many, but Public assistances are practical and doable. Even though the CCDC [30] is a "weak link" in the 
deliverance of Public Space. The cultural district in Downtown area is distinguishable, the human attraction and life quality play a turmoil role in fostering development of knowledge economy and shifting the cultural ranking of San Diego city forward.

Acknowledgment. "This work is part of the MAPS-LED research project, which has received funding from the European Union's Horizon 2020 research and innovation programme under the Marie Skłodowska-Curie grant agreement No 645651”.

\section{References}

1. Moulaert, F., et al.: General introduction: the return of social innovation as a scientific concept and a social practice. In: The International Handbook on Social Innovation, Collective Action, Social Learning and Transdisciplinary Research, pp. 1-153 (2013)

2. MAPS-LED Project: S3: Cluster Policy And Spatial Planning. Knowledge Dynamics, Spatial Dimension And Entrepreneurial Discovery Process. Second Scientific Report, MAPS-LED Project, Multidisciplinary Approach to Plan Smart specialisation strategies for Local Economic Development, Horizon 2020 - Marie Swlodowska Curie Actions -RISE 2014 -grant agreement 645651, pp. 9-23 (2017)

3. Evans, G.: Creative cities, creative spaces and urban policy. Urban Stud. 46, 1003-1040 (2009)

4. Mercer, C.: Cultural planning for urban development and creative cities. In: Shanghai Cultural Planning Conference, 3 (2006). http://www.kulturplan-oresund.dk/pdf/Shanghai_ cultural_planning_paper.pdf. Accessed 21 Nov 2017

5. Florida, R.: The Rise of the Creative Class: and How It's Transforming Work, Leisure, Community and Everyday Life. Basic Books, New York (2002). http://www. washingtonmonthly.com/features/2001/0205.florida.html. Accessed 21 Nov 2017

6. Deffner, A., Vlachopoulou, C.: Creative city: a new challenge of strategic urban planning? In: ERSA Conference Papers, pp. 1-14 (2011). http://ideas.repec.org/p/wiw/wiwrsa/ ersa11p1584.html. Accessed 21 Nov 2017

7. Florida, R.: The New Urban Crisis. Edited by Martin Prosperity institute, Basic Books (2017)

8. Mallach, A.: Lots of Maps, Little Insight in Richard Florida's Latest, Shelterforce, pp. 20 22, 11 May 2017. https://shelterforce.org/2017/05/11/lots-of-maps-little-insight-in-richardfloridas-latest/. Accessed 21 Nov 2017

9. UN-HABITAT, Global Public Space Toolkit: From Global Principles to Local Policies and Practice. https://unhabitat.org/books/global-public-space-toolkit-from-global-principles-tolocal-policies-and-practice/. Accessed 21 Nov 2017

10. European Commission LEIPZIG CHARTER on Sustainable European Cities (2007). http:// www.eu2007.de/en/News/download_docs/Mai/0524-AN/075DokumentLeipzigCharta.pdf. Accessed 21 Nov 2017

11. Moulaert, F., et al.: Towards alternative model(s) of local innovation. Urban Stud. 42(11), 1969-1990 (2005). http://journals.sagepub.com.ezproxy.neu.edu/doi/pdf/10.1080/00420980 500279893. Accessed 21 Nov 2017

12. Mehmood, A., Parra, C.: Social innovation in an unsustainable world. In: Moulaert, F., MacCallum, D., Mehmood, A. (eds.) The International Handbook on Social Innovation: Collective Action, Social Learning and Transdisciplinary Research, pp. 53-66. Edward Elgar, Cheltenham (2013) 
13. Shockley, G.: Book review: The international handbook on social innovation: collective action, social learning and transdisciplinary research. J. Reg. Sci. 152-153 (2015). Wiley

14. DSDP: Downtown San Diego: the innovation economy's next Frontier A data driven exploration of San Diego's Urban renaissance. San Diego: UC San Diego extension center for research on the regional economy (2016). http://downtownsandiego.org. Accessed 21 Nov 2017

15. US Census Bureau American Community Survey, American FactFinder. http://factfinder2. census.gov. Accessed 18 May 2017

16. Showley, R.: Gensler: Redesigning San Diego, from North to South, The San Diego Union-Tribune, pp. 1-4, May 2017. http://www.sandiegouniontribune.com/business/growthdevelopment/sd-fi-gensler-20170508-story.html. Accessed 21 Nov 2017

17. DSDP Imagine Downtown, San Diego. http://downtownsandiego.org/wp-content/uploads/ 2015/02/Imagine-Downtown-Presented-by-the-Downtown-San-Diego-Partnership.pdf.

Accessed 21 Nov 2017

18. DSDP Update, Imagine Downtown, San Diego. http://downtownsandiego.org/wp-content/ uploads/2015/02/Imagine-Downtown-Presented-by-the-Downtown-SanDiego-Partnership. pdf. Accessed 21 Nov 2017

19. DSDP. https://dsdp2015.carto.com/viz/4bb5a924-fd10-11e5-92ce-0e3ff518bd15/public_ map. Accessed 21 Nov 2017

20. Dwyer, M.C., Beavers, K.A.: How the arts and culture sector catalyzes economic vitality, American Planning Association. Edited by Murray, D.J. (2015). https://www.planning.org/ research/arts/briefingpapers/vitality.htm. Accessed 21 Nov 2017

21. Lothspeich, D.: Quartyard's New Lease on Life, SoundDiego: Music, Community, Culture (2017). http://www.nbcsandiego.com/blogs/sounddiego/Quartyard-Lands-New-Location421784253.html. Accessed 15 May 2017

22. SDtechscene Downtown Works. http://sdtechscene.org/venues/downtown-works/. Accessed: 1 June 2017

23. Downtown Works, CoWork with us! Lightpost Digital. http://www.downtownworks.com/. Accessed 1 June 2017

24. The San Diego Union Tribune, A city of great public spaces. http://www. sandiegouniontribune.com/opinion/editorials/sdut-a-city-of-great-public-spaces-2011jan16story.html. Accessed 1 June 2017

25. CONNECT, San Diego Innovation Report. http://www.connect.org/innovation-reports. Accessed 1 June 2017

26. Equinox Entrepreneurship How are we doing? Center for Sustainable Enegrgy. https:// energycenter.org/equinox/dashboard/entrepreneurship\#indicator-idea. Accessed 20 May 2017

27. Morelix, A., Fairlie, R., Tareque, I.: Kauffman Index of Startup Activity: Metropolitan area and City Trends (2017). https://www.KauffmanIndex.org. Accessed 1 June 2017

28. Feldman, M.P.: The character of innovative places: entrepreneurial strategy, economic development, and prosperity. Small Bus. Econ. 43(1), 9-20 (2014)

29. Hesmondhalgh, D., Pratt, A.C.: Cultural industries and cultural policy'. Int. J. Cult. Policy 11(1), 1-13 (2005)

30. CCDC, Centre City Development Corporation: Downtown San Diego Public Open Space Implementation Plan PART 1: Project Initiation, Data Analysis And Synthesis. San Diego. http://civicsd.com/wp-content/uploads/2015/02/POSIP_Part_I_Summary_Report.pdf.

Accessed 20 May 2017 